\title{
Delusional disorder: The role of personality and emotions on delusional ideation
}

\author{
Matteo Tonna ${ }^{\text {b,* }}$, Francesca Paglia ${ }^{\text {a }}$, Rebecca Ottoni ${ }^{\text {, }}$, Paolo Ossola a ${ }^{\text {, Chiara De Panfilis }}{ }^{\text {a,b }}$, Carlo Marchesi ${ }^{\text {a,b }}$ \\ a Department of Neuroscience, Psychiatric Unit, University of Parma, Italy \\ b Department of Mental Health, Local Health Service, Parma, Italy
}

\begin{abstract}
A B S T R A C T
The relationship between personality and Delusional Disorder in still debated. The present study aimed to evaluate the role of personality features and emotional dispositions on the proneness to delusional beliefs, through the lens of a dimensional approach.

91 outpatients were administered the Structured Interview for DSM-IV Personality Disorders, the Pathological Narcissism Inventory, the Positive and Negative Affect Schedule and the Peters et al. Delusions Inventory. Delusion proneness was positively related to the "Hiding the Self" domain of narcissistic vulnerability and to paranoid traits and negatively related to "Positive Affect". Paranoid traits and "Hiding the Self" significantly interacted in influencing delusion ideation.

These data suggest that proneness to delusion depends, at least in part, on a complex interplay between specific emotional and paranoid dispositions within personality.
\end{abstract}

(c) 2018 Elsevier Inc. All rights reserved.

\section{Introduction}

The term "paranoia" refers to Kraepelin's conceptualization of a third functional psychosis, distinct from either "dementia praecox" or manicdepressive illness [1]. Typically delusions are systematic (i.e. are elaborated through logical thinking), tend to become chronic with preservation of personality and relate to interpersonal interactions and essential human experience $[2,3]$.

Kraepelinian definition of paranoia had a huge influence in modelling the current diagnostic criteria of "Delusional Disorder (DD)" (DSM III-5) [4].

Although DD is categorically described, delusional beliefs exist as a continuous phenotype, with a dimensional structure rather than an allor-nothing fashion [5-8]. Along a severity gradient, a gradual transition can be traced from delusion-like experiences (DLEs) (e.g. subthreshold delusional beliefs such as mild self-reference experiences and non-clinical paranoid ideation) $[9,10]$ at the one end, to a full-blown DD posited at the opposite end. As claimed by van Os and colleagues, altogether these data suggest that "the search for the determinants of the psychosis phenotype should be conducted along broad dimensional lines, in addition to the more narrow focus on the clinical definition".

Along a delusion continuum, specific personality traits might be involved in the transition from sub-threshold experiences to clinical

\footnotetext{
* Corresponding author at: University of Parma, Department of Neuroscience, Psychiatry Unit, Ospedale Maggiore, Padiglione Braga, Viale A. Gramsci 14, 43126 Parma, Italy.

E-mail address: mtonna@ausl.pr.it (M. Tonna).
}

delusions, as suggested by both classical psychopathology [11-13] and recent research [3]. Consistently, grandiose and narcissistic traits of personality have been traditionally associated with paranoia [13, 14]. Moreover, a high prevalence of personality disorders (PDs) has been found in DD patients, with a rate ranging from $39.5 \%$ to $64 \%[15,16]$. The most frequent PD comorbidity concerns Paranoid (38.4\%), Schizoid (12.8\%), Obsessive-Compulsive (11.2\%) and Avoidant (9.8\%) Disorders [16].

In the search of trait variables of delusional proneness, different perspectives have been examined, particularly psychodynamic (defensive mechanisms of denial and projection) $[17,18]$ and cognitive approaches (theory of mind alterations, probabilistic reasoning or attributional biases hypotheses) [19].

By contrast, the role of emotions in the development of DD is lacking, even though delusions appear to have a strong emotional component [20]; for instance, a vicious circle between cognitive biases and emotional disturbances may be involved in delusional patients [9]. Particularly, worry processing and rumination are associated with DLEs in healthy individuals [21] and increase anomalous experiences in delusional patients [22]. Therefore, in delusion phenomena "emotional processes must be given special consideration, even if their exact role is not well understood yet" [2].

In this connection, Kretschmr [12], a pioneer in the study of DD, emphasized the role of emotional vulnerabilities associated with specific personality traits in the development of delusions.

Particularly, this Author described a specific type of DD, the "sensitive delusion of reference", developing from an underlying "sensitive" personality with "asthenic" traits (feelings of inadequacy and shame, 
as well as apathy and fatigue) coexisting with "sthenic" dispositions (i.e. abnormal sensitivity to criticism and grandiose fantasies).

Kretschmer's asthenic-sthenic polarity of sensitive character anticipates the dichotomy between "humiliating shame" and "relentless anger" of narcissistic pathology proposed by Kohut [23] as well as Gabbard's "hypervigilant narcissism" [24] (which refers to a hyperevaluation of the self with tendency to grandiose fantasy covering shyness, social inhibition and shame).

The more recent model of narcissism vulnerability [25] encompasses most of the above-mentioned personality features, its personality structure being characterized by emotional dysregulation, feelings of inadequacy, hypersensitivity to rejection, and social withdrawal when one's needs for admiration are not met [26].

Interestingly, shame appears to be related to narcissistic injury [27] and associated with higher levels of paranoid ideation $[28,29]$ in general population. By contrast, resistance to experiencing shame could be a marker of resilience [30].

Altogether, these findings suggest that paranoid symptoms might develop from an interaction between specific personality traits and emotional dispositions. To date, studies that investigated this interaction are lacking.

Therefore, the present study aimed to investigate, adopting a dimensional approach, the role of personality traits and emotional disturbances on delusion ideation in a clinical sample of subjects referring to the outpatient unit of the University of Parma.

\section{Methods}

\subsection{Sample}

The present study recruited outpatients referring to the Personality Disorders Unit of the University Hospital of Parma from January 2014 and December 2015.

The study sample was preselected in order to guarantee that the entire delusional continuum could be represented.

Patients were included in the study if they met the following criteria: 1 ) their age was over $18 ; 2$ ) their written informed consent was obtained. Patients were excluded from the study if they were affected by: 1) a current mental disorder related to a general medical condition; 2) cognitive impairment (Mini-Mental State Examination score lower than 25) which interfered with the ability to reliably complete diagnostic interviews or questionnaires; 3 ) substance or alcohol abuse or dependence.

Delusional ideation is a psychopathological experience that cuts across different disorders (from schizophrenia to affective disorders or acute psychoses); since the aim of the present study was to deepen the role of personality and emotions specifically in Delusional Disorder, other Axis I diagnoses that could present with delusional ideation were excluded from the study.

All patients have been provided a complete and exhaustive description of the study after the achievement of clinical stabilization.

\section{Procedures}

Demographic information about participants has been collected during the enrolment through a specific schedule that included gender, age, educational level, marital, occupational and living status. The diagnoses of axis I disorder were assessed using the Structured Clinical Interview for DSM-IV axis I disorder, clinical version (SCID-I CV) [31, 32].

All patients completed the Structured Interview for DSM-IV Personality Disorders (SIDP-IV) [33] for the assessment of personality. The Pathological Narcissism Inventory - Italian Version (PNI) [25,34] was adopted to investigate grandiose and vulnerable themes of narcissistic pathology. The PNI is a 52-item self-report measure assessing 7 dimensions of pathological narcissism spanning problems with narcissistic grandiosity (Entitlement Rage, Exploitativeness, Grandiose Fantasy,
Self-sacrificing Self-enhancement) and narcissistic vulnerability (Contingent Self-esteem, Hiding the Self, Devaluing) [25].

The Positive and Negative Affect Schedule (PANAS) [35] was used as measure of Positive Affectivity (PA) and Negative Affectivity (NA).

Finally, the Peters et al. Delusions Inventory - Italian Version (PDI21) [36] was adopted to evaluate the severity gradient of delusional ideation since its validity in both clinical and non-clinical population [37]. Because the absolute prevalence of answers on the PDI items influences the scores on the 3 subscales, following previous research [38] a "weighted" score for these dimensional subscales was calculated by dividing the total values by the number of endorsed items on the PDI main queries.

The assessment of premorbid personality traits was also based on information collected from relatives. They were specifically interviewed about the patient's behavior in a wide range of social situations in the 5 years before the enrollment in the study.

Personality and psychopathological evaluations were carried out by a trained psychiatrist only if the patient presented a stable clinical picture, in order to allow a valid collaboration.

Personality traits rather than disorders were considered because the number of personality categories found in each subgroup of patients was too small to allow reliable evaluations. Moreover, a dimensional approach is thought to be superior to a categorical model, especially for research purposes [39]; for example, traits are more stable than categories over time $[40,41]$

With specific regard to the emotional component, we ought to test the "asthenic-sthenic" model of Kretschmer's sensitive character investigating traits of narcissism pathology [25], as well as through the model of Positive (PA) and Negative (NA) Affectivity [35]. PA and NA are the two dominant dimensions in self-reported mood [42] and, viewed as a trait, represent stable individual differences in general affective tone [43].

\subsection{Statistical analysis}

We first evaluated the normal distribution of the variable and subsequently analysed the correlations, with Pearson's and Spearman's coefficients where appropriate, between personality traits (SIDP-IV), levels of pathological narcissism dimensions (PNI), Positive and Negative Affectivity dimensions (PANAS) and severity of delusional ideation (PDI score). Significant correlation was subsequently entered in a linear regression model (Enter method) to evaluate the effect of personality traits (SIDP-IV scores), levels of pathological narcissism (PNI subscales), general affective tone (PANAS subscales) and socio-demographic features (independent variables) on PDI scores (dependent variables). Significant interactions between independent variables in the prediction of the outcomes (i.e. delusional dimension severity as dependent variable), were further explored in a moderation analyses using PROCESS for SPSS (Model \#1) [44] co-varying as appropriate. All statistical analyses were performed with SPSS for Windows (version 25.0, SPSS Inc., Chicago, IL, USA).

\section{Results}

\subsection{Participants}

The present study included 91 subjects ( 31 males; $34.1 \%$; mean age: $48.8 \pm 13.3$ years); 36 patients (39.\%; PDI score $17.46 \pm 1.01$; age $51.8 \pm 12.25$ years) received a diagnosis of DD (DSM-IV-TR) [4]. The socio-demographical and clinical features of the study sample are reported in Table 1.

\subsection{Correlations}

The patterns of correlation among the study variables in the overall sample are reported in Table 2. Paranoid, Schizotypal and ObsessiveCompulsive personality traits resulted positively associated with 
Table 1

Socio-demographic and clinical features of the sample.

\begin{tabular}{ll}
\hline & Overall sample \\
\hline & $\mathrm{n} .91$ \\
Age & $48.76 \pm 13.34$ \\
Education years & $11.75 \pm 3.87$ \\
Gender & \\
Female & $60(65.9 \%)$ \\
Marital status & \\
Single & $34(37.4 \%)$ \\
Married & $38(41.8 \%)$ \\
Separated/divorced & $13(14.3 \%)$ \\
Widow & $6(6.6 \%)$ \\
Living status & \\
Alone & $24(26.4 \%)$ \\
With partner & $45(49.5 \%)$ \\
With parents & $1819.8 \%)$ \\
Other situations & $4(4.4 \%)$ \\
Working status & \\
Employed/student & $74(81.3 \%)$ \\
Unemployed & $17(18.7 \%)$ \\
Personality features & \\
Cluster A & \\
Paranoid traits & \\
Schizoid traits & $1.82 \pm 2.12$ \\
Schizotypal traits & $0.30 \pm 0.84$ \\
Cluster B & $0.58 \pm 1.28$ \\
Borderline traits & \\
Narcissistic traits & \\
Histrionic traits & \\
Antisocial traits & $0.75 \pm 1.43$ \\
Cluster C & $1.08 \pm 1.65$ \\
Avoidant traits & $0.65 \pm 1.24$ \\
Dipendent traits & \\
Obsessive-compulsive traits & \\
PANAS & \\
PA & $0.70 \pm 1.46$ \\
NA & $0.32 \pm 0.77$ \\
PNI tot & $1.84 \pm 2.09$ \\
CSE & \\
EXP & $29.02 \pm 10.32$ \\
SSSE & $23.99 \pm 8.88$ \\
GF & $12.03 \pm 6.05$ \\
DEV & $2.22 \pm 1.28$ \\
ER & $1.40 \pm 1.09$ \\
NV & $1.20 \pm 0.84$ \\
NG & $2.60 \pm 1.37$ \\
\hline & $1.33 \pm 0.98$ \\
& $1.21 \pm 1.04$ \\
& $1.54 \pm 1.08$ \\
& $13.20 \pm 7.83$ \\
& $10.29 \pm 4.72$ \\
\hline
\end{tabular}

delusional severity (PDI score). A negative association was found between Positive Affectivity dimension score (PA; PANAS subscale) and delusional ideation (PDI score), whereas a positive association was found between "Hiding the Self" subscale (HS; PNI subscale) and delusional dimension severity (PDI score).

\subsection{Personality traits, emotions and severity of delusions}

Linear regression showed that the severity of delusional ideation (PDI scores, dependent variable) was positively related to HS (B = 1.59; CI 95\% [0.59;3.05]; $p=.006)$ and to paranoid traits $(\mathrm{B}=1.37 ; \mathrm{CI}$ $95 \%[0.82 ; 2.08] ; p=.050)$ and negatively related to $\mathrm{PA}(\mathrm{B}=-0.146$; CI 95\% [-0.30; -0.04$] ; p=.024$ ) (Table 3).

Therefore, we explored the possible interaction between the aforementioned variables.

\subsection{Moderation analysis}

Given the significant interaction, we evaluated whether HS and PA interacted with paranoid personality traits on delusional dimension (PDI score), following Hayes procedure for assessing conditional effects of the moderator (PROCESS Model \#1). Only HS interacted with paranoid traits in predicting PDI score (interaction HS mean score*paranoid traits: $\mathrm{B}=-0.70, \mathrm{SE}=0.18,95 \% \mathrm{CI}=[-1.05 ;-0.34], p=.000$; interaction $\mathrm{PA} *$ paranoid traits: $\mathrm{B}=-0.01, \mathrm{SE}=0.03,95 \% \mathrm{CI}[-0.03$; 1.87], $p=.06$ ) (Table 4; Fig. 1).

\section{Discussion}

The aim of the present study was to evaluate the role of personality and emotional disturbances on delusional ideation in a clinical sample of outpatients representative of the entire delusional continuum.

To our knowledge, this is the first study adopting a dimensional approach to investigate the relationship between personality, emotions and delusional proneness. Moreover, to date studies that evaluated the relationship between specific PDs and DD are scarce [16]; none of them considering the emotional component of delusions. In fact, previous studies explored the association between delusions and affectivity (especially mood symptoms) $[45,46]$, thus neglecting a broader spectrum of emotional dispositions (such as shame), strongly associated to DD.

With specific regard to premorbid personality, in the present study, higher paranoid, schizotypal and obsessive-compulsive traits were associated with a higher severity in delusional continuum. These data are in line with previous studies [16] and support the hypothesis that specific personality traits are related to delusions. Personality features evaluated in the present study represent stable premorbid traits rather than a possible artifact due to a state condition since: 1) personality traits are more stable than categories and less influenced by the state of illness [40,41]; 2) personality was evaluated collecting data about patients' social behavior in the last 5 years and through external informants.

Therefore, this study finding suggests that the severity of delusional beliefs depends, at least in part, on premorbid personality; in other words, specific personality traits may predispose to more severe delusional experience, thus supporting the view that delusional ideation may develop from predisposing personality features $[11,12,16]$.

Concerning the hypothesis that specific emotions may be associated with delusional beliefs, the present study would confirm this relationship: the severity of delusional ideation resulted negatively associated with PANAS - Positive Affect (PA) and positively with PNI - Hiding the Self (HS). PA reflects the extent to which a person feels enthusiastic, active, and alert. High PA is a state of high energy, full concentration, and pleasurable engagement, whereas low PA is characterized by sadness and lethargy [47]. Conversely, HS reflects an unwillingness to show others own faults and needs and resulted closely related to the experience of shame $[25,48]$. Noteworthy, both PANAS and PNI scales are adopted to capture stable emotional and cognitive components of personality, in order to minimize a possible "state" effect.

We speculate that lower levels of PA and higher levels of HS may remind the specific emotional component of Kretschmer's sensitive character (particularly its affective nucleus of inadequacy and shame as well as of fatigue and exhaustibility).

Furthermore, these results are consistent with previous studies suggesting a role of negative emotions (particularly depression) in the development of full-blown psychotic symptoms from sub-threshold psychotic experiences [49-53] or from peculiar personality traits [54, 55].

Moreover, the association between higher levels of HS and delusion ideation confirms the clinical prominence of vulnerable characteristics of narcissism [56]. The lack of association between delusion severity and narcissistic traits in the present study may be due to the increasingly narrow criteria of DSM Narcissistic Personality Disorder, which are mainly focused on grandiosity [57]. The DSM narrow criteria likely contribute to the low-prevalence rate of narcissistic traits in the study sample as well as in clinical practice [56].

Since HS is closely related to the experience of shame, these results are in line with the hypothesis that shame is associated with delusion proneness in both clinical [30] and non-clinical samples [28,29]. From a phenomenological perspective, shame shows a double polarity: an objective pole, represented by an observing and judging external eye and a subjective one, dealing with the exposure of inner feelings of self- 
Table 2

Spearman's correlation among primary variables of the study.

\begin{tabular}{|c|c|c|c|c|c|c|c|c|c|c|c|c|c|c|c|c|c|c|c|c|c|c|}
\hline & 1. & 2. & 3. & 4. & 5. & 6. & 7. & 8. & 9. & 10. & 11. & 12. & 13. & 14. & 15. & 16. & 17. & 18. & 19. & 20. & 21. & 22. \\
\hline 1. PDI & - & & & & & & & & & & & & & & & & & & & & & \\
\hline 2. PA & $-0.225^{*}$ & - & & & & & & & & & & & & & & & & & & & & \\
\hline 3. NA & 0.0372 & -0.031 & - & & & & & & & & & & & & & & & & & & & \\
\hline 4. PNI & 0.076 & 0.041 & $0.442^{* *}$ & - & & & & & & & & & & & & & & & & & & \\
\hline 5. HS & $0.279^{* *}$ & -0.179 & $0.322^{* *}$ & $0.691^{* *}$ & - & & & & & & & & & & & & & & & & & \\
\hline 6. CSE & -0097 & -0.076 & $0.451^{* *}$ & $0.848^{* *}$ & $0.516^{* *}$ & - & & & & & & & & & & & & & & & & \\
\hline 7. EXP & -0.140 & $0.223^{*}$ & 0.048 & $0.300^{* *}$ & 0.078 & 0.076 & - & & & & & & & & & & & & & & & \\
\hline 8. SSSE & -0.008 & 0.154 & $0.255^{*}$ & $0.721^{* *}$ & $0.442^{* *}$ & $0.520^{* *}$ & 0.144 & - & & & & & & & & & & & & & & \\
\hline 9. GF & 0.0057 & 0.199 & 0.186 & $0.612^{* *}$ & $0.281^{* *}$ & $0.420^{* *}$ & $0.461^{* *}$ & $0.334^{* *}$ & - & & & & & & & & & & & & & \\
\hline 10. DEV & -0.045 & 0.098 & $0.477^{* *}$ & $0.798^{* *}$ & $0.492^{* *}$ & $0.686^{* *}$ & 0.176 & $0.535^{* *}$ & $0.479^{* *}$ & - & & & & & & & & & & & & \\
\hline 11. ER & 0.027 & 0.151 & $0.432^{* *}$ & $0.756^{* *}$ & $0.455^{* *}$ & $0.585^{* *}$ & $0.283^{* *}$ & $0.405^{* *}$ & $0.457^{* *}$ & $0.683^{* *}$ & - & & & & & & & & & & & \\
\hline 12. NG & -0.055 & $0.266^{*}$ & $0.211^{*}$ & $0.795^{* *}$ & $0.387^{* *}$ & $0.528^{* *}$ & $0.563^{* *}$ & $0.775^{* *}$ & $0.762^{* *}$ & $0.531^{* *}$ & $0.499^{* *}$ & - & & & & & & & & & & \\
\hline 13. NV & 0.0793 & -0.039 & $0.488^{* *}$ & $0.956^{* *}$ & $0.732^{* *}$ & $0.895^{* *}$ & 0.142 & $0.593^{* *}$ & $0.466^{* *}$ & $0.818^{* *}$ & $0.771^{* *}$ & $0.601^{* *}$ & - & & & & & & & & & \\
\hline 14.PARND & $0.450^{* *}$ & 0.039 & 0.046 & -0.078 & -0.045 & -0.014 & -0.009 & -0.197 & -0.039 & -0.046 & 0.084 & -0.125 & -0.013 & - & & & & & & & & \\
\hline 15. SZOID & 0.115 & 0.043 & 0.110 & -0.002 & -0.034 & -0.019 & -0.018 & -0.053 & -0.039 & 0.080 & 0.172 & -0.050 & 0.049 & 0.135 & - & & & & & & & \\
\hline 16.STYPL & $0.259^{* *}$ & 0.013 & 0.072 & -0.069 & 0.071 & -0.009 & 0.029 & $-0.240^{*}$ & -0.094 & -0.010 & 0.032 & -0.179 & 0.017 & $0.333^{* *}$ & $0.273^{* *}$ & - & & & & & & \\
\hline 17.BORDL & -0.0651 & 0.087 & $0.276^{* *}$ & 0.049 & -0.081 & 0.143 & 0.138 & -0.126 & 0.117 & 0.093 & 0.190 & -0.001 & 0.098 & $0.284^{* *}$ & $0.246^{*}$ & $0.307^{* *}$ & - & & & & & \\
\hline 18. NARCI & 0.092 & $0.272^{* *}$ & 0.041 & 0.127 & -0.010 & -0.016 & 0.191 & -0.003 & $0.322^{* *}$ & 0.155 & $0.239^{*}$ & 0.200 & 0.096 & $0.396^{* *}$ & $0.216^{*}$ & $0.231^{*}$ & $0.209^{*}$ & - & & & & \\
\hline 19. HISTR & -0.014 & 0.179 & -0.004 & 0.014 & -0.137 & -0.071 & $0.231^{*}$ & 0.020 & 0.097 & -0.030 & 0.093 & 0.130 & -0.028 & 0.140 & 0.143 & 0.186 & $0.403^{* *}$ & $0.370^{* *}$ & - & & & \\
\hline 20. AVOID & 0.045 & -0.023 & 0.196 & $0.266^{*}$ & 0.205 & $0.283^{* *}$ & 0.148 & 0.155 & 0.132 & 0.101 & 0.126 & $0.224^{*}$ & $0.263^{*}$ & 0.092 & -0.116 & $0.211^{*}$ & $0.279^{* *}$ & 0.082 & 0.000 & - & & \\
\hline 21. DEPEN & 0.0075 & -0.074 & $0.226^{*}$ & $0.221^{*}$ & 0.050 & $0.256^{*}$ & -0.069 & $0.276^{* *}$ & 0.037 & 0.167 & 0.183 & 0.142 & $0.235^{*}$ & -0.004 & $0.233^{*}$ & 0.009 & $0.266^{*}$ & -0.069 & 0.070 & $0.537^{* * *}$ & - & \\
\hline 22.0BCMP & $0.266^{*}$ & -0.027 & 0.109 & -0.028 & -0.015 & -0.016 & -0.053 & -0.069 & -0.020 & -0.037 & 0.074 & -0.070 & 0.018 & $0.504^{* *}$ & 0.151 & $0.297^{* *}$ & $0.351^{* *}$ & $0.380^{* *}$ & 0.133 & $0.343^{* *}$ & 0.188 & - \\
\hline
\end{tabular}

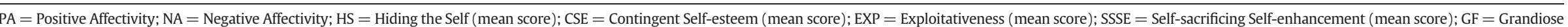

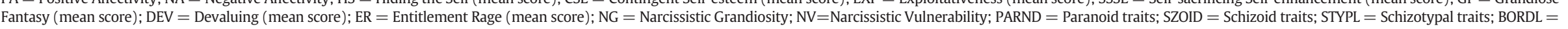
Borderline traits; $\mathrm{NARCI}=$ Narcissistic traits; HISTR = Histrionic traits; AVOID = Avoidant traits; DEPEN = Dependent traits; OBCMP=Obsessive Compulsive traits.

$\begin{aligned} * * & =.01 \\ * & =.05\end{aligned}$ 
Table 3

Effect of "Hiding the Self" dimension, "Positive Affectivity" dimension and paranoid traits on severity of delusion (PDI Score).

\begin{tabular}{lcrrr}
\hline PDI total score & & & & \\
\hline & B [95\%CI] & SE & t & p \\
\hline STEP 1 & & & & \\
Positive Affectivity & $11.67[6.18 ; 16.95]$ & 0.06 & -1.90 & $\mathbf{0 . 0 0 0}$ \\
Hiding the Self & $1.54[0.56 ; 2.83]$ & 0.57 & 2.80 & 0.007 \\
STEP 2 & & & & \\
Positive Affectivity & $0.146[-0.304 ;-0.309]$ & 0.07 & -2.44 & $\mathbf{0 . 0 2 4}$ \\
Hiding the Self & $1.59[0.59 ; 3.05]$ & 0.56 & 3.32 & $\mathbf{0 . 0 0 6}$ \\
Paranoid traits & $1.37[0.82 ; 2.08]$ & 0.27 & 4.26 & $\mathbf{0 . 0 0 0}$ \\
Scizotypal traits & $0.86[-0.22 ; 1.62]$ & 0.46 & 1.75 & $\mathbf{0 . 0 5 0}$ \\
Obsessive-Compulsive traits & $0.21[-0.48 ; 0.87]$ & 0.34 & 0.66 & 0.514 \\
\hline
\end{tabular}

deficiency and inadequacy $[58,59]$. We speculate, following either phenomenological [12] or psychodynamic theories [23], that shame may constitute the emotional core of paranoid ideation.

Interestingly, the effect of paranoid traits, HS and PA on severity of delusional dimension was independent from each other, with paranoid traits being the strongest predictor of delusional severity. This finding is consistent with previous studies that emphasize a close relationship between Paranoid PD and DD [60-62].

Finally, we sought to test the hypothesis that personality traits (paranoid) and specific emotional dispositions (PA and HS) interact in influencing the severity of delusional ideation.

We found a significant interaction between paranoid traits and HS in predicting the severity of delusional dimension. Particularly, paranoid traits were positively associated with delusional ideation only at low or moderate HS scores; the effect ceased with high HS scores. Therefore, the study finding suggests, confirming previous research [63], that delusional proneness is mainly attributable to paranoid traits, but with emotional dispositions having a moderating role in the development to delusional beliefs.

The strengths of the present study are: 1) the inclusion in the study sample of the whole range of delusional ideation along a severity continuum; 2) the adoption of a dimensional model for the personality assessment; 3) the investigation of the emotional component of delusional beliefs.

The present study should be considered in light of some limitations. First, caution should be used in drawing firm conclusions from this study due to its small sample size and composition (subjects enrolled were representative of a clinical sample of outpatients referring to a Personality Disorders Unit). Second, the cross-sectional design of the study cannot rule out the possibility that the interplay between delusional ideation and emotional components of personality may change over time or may have a phase-dependent effect. Future research should be addressed to larger cohorts of non-clinical population, adopting a longitudinal perspective.

In conclusion, the present study suggests that delusional ideation depends on a complex interplay between specific emotional and

\section{Table 4}

HS moderates the relationship between paranoid traits and the severity of delusion ideation (PDI Score).

\begin{tabular}{lccrl}
\hline & B $[\mathbf{9 5 \%} \mathbf{~ C I}]$ & SE & \multicolumn{1}{c}{ t } & p \\
\hline HS & $1.52[0.59 ; 2.44]$ & 0.47 & 3.27 & $\mathbf{0 . 0 0 1}$ \\
Paranoid traits & $1.35[0.78 ; 1.91]$ & 0.28 & 4.74 & $\mathbf{0 . 0 0 0}$ \\
HS * Paranoid traits & $-0.81[-1.39 ;-0.24]$ & 0.29 & -2.80 & $\mathbf{0 . 0 0 6}$ \\
Schizotypal traits & $0.85[-0.29 ; 1.99]$ & 0.57 & 1.48 & 0.142 \\
PA & $-0.13[-0.25 ;-0.01]$ & 0.06 & -2.07 & $\mathbf{0 . 0 4 1}$ \\
Conditional Effect on PDI total score & & & & \\
\hline$\quad$ Low paranoid traits: -1.28 & $2.39[1.40 ; 3.37]$ & 0.50 & 4.82 & $\mathbf{0 . 0 0 0}$ \\
HS $\times$ Med paranoid traits: 0.00 & $1.35[0.78 ; 1.91]$ & 0.28 & 4.74 & $\mathbf{0 . 0 0 0}$ \\
$\quad$ High paranoid traits: 1.28 & $1.28[-0.56 ; 1.17]$ & 0.44 & 0.70 & 0.488 \\
\hline
\end{tabular}

Note. $n=91$; HS = Hiding the Self (mean score); PA = Positive Affectivity; Model $\mathrm{R}^{2}=$ $0.66, \mathrm{~F}(5,85)=14.12, p=.00$; HS score moderator values represent the mean and $\pm 1 \mathrm{SD}$.

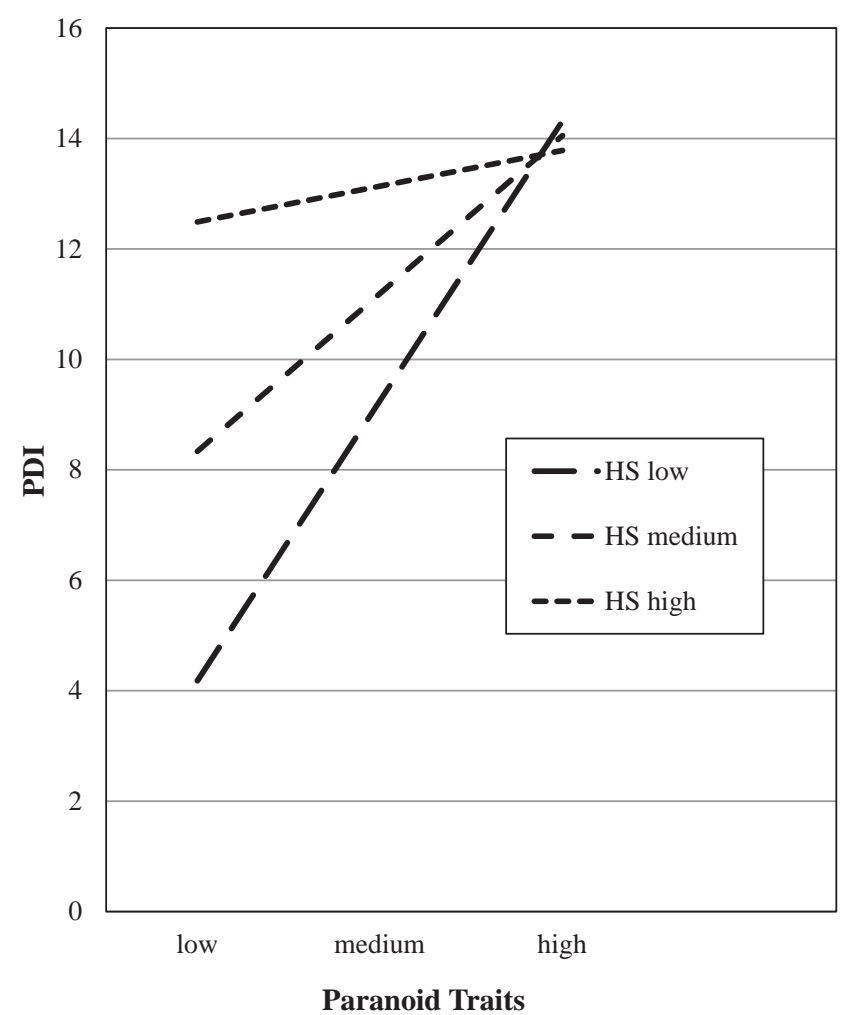

Fig. 1. Interaction between HS mean score and paranoid traits on the severity of delusion ideation (PDI Score).

paranoid dispositions within personality structure. From this viewpoint, delusion may constitute the superficial shell, which develops from and cover inner emotional vulnerabilities of personality.

\section{Conflict of interest and founding source}

This research did not receive any specific grant from funding agencies in the public, commercial, or not-for-profit sectors.

\section{References}

[1] Kraepelin E. Psychiatrie ein lehrbuch für studierende und ärzte, ed 4. Leipzig: Barth; 1893.

[2] Kunert HJ, Norra C, Hoff P. Theories of delusional disorders. An update and review psychopathology 2007;40:191-202.

[3] Opjordsmoen S. Delusional disorder as a partial psychosis. Schizophr Bull 2014;40: 244-7. https://doi.org/10.1093/schbul/sbt203.

[4] American Psychiatric Association. Diagnostic and statistical manual of mental disorders (DSM5). 5th ed. Washington, DC: American Psychiatric Press; 2013.

[5] Strauss JS. Hallucinations and delusions as points on continua function rating scale evidence. Arch Gen Psychiatry 1969;21:581-6.

[6] Sacks MH, Carpenter WT, Strauss JS. Recovery from delusions: three phases documented by patient's interpretation of research procedures. Arch Gen Psychiatry 1974;30:1117-20.

[7] Eisen JL, Phillips KA, Baer L, Beer DA, Atala KD, Rasmussen SA. The brown assessment of beliefs scale: reliability and validity. Am J Psychiatry 1998;155:102-8.

[8] van Os J, Hanssen M, Bijl RV, Ravelli A. Strauss (1969) revisited: a psychosis continuum in the general population? Schizophr Res 2000;45:11-20.

[9] Gawęda Ł, Prochwicz K. A comparison of cognitive biases between schizophrenia patients with delusions and healthy individuals with delusion-like experiences. Eur Psychiatry 2015;30:943-9. https://doi.org/10.1016/j.eurpsy.2015.08.003.

[10] Yung AR, Lin A. Psychotic experiences and their significance. World Psychiatry 2016; 15:130-1.

[11] Jaspers K. Allgemeine Psychopathologie. Berlin: Springer; 1913.

[12] Der Kretschmer E. Sensitive Beziehungswahn. Berlin: Springer; 1918.

[13] Schneider K. Die Psychopathischen Persönlichkeiten. Wien: Leipzig; 1923.

[14] Joiner Jr TE, Petty S, Perez M, Sachs-Ericsson N, Rudd MD. Depressive symptoms induce paranoid symptoms in narcissistic personalities (but not narcissistic symptoms in paranoid personalities). Psychiatry Res 2008;159:237-44. 
[15] Newton-Howes G, Tyrer P, North B, Yang M. The prevalence of personality disorder in schizophrenia and psychotic disorders: systematic review of rates and explanatory modelling. Psychol Med 2008;38:1075-82.

[16] De Portugal E, González N, del Amo V, Haro JM, Díaz-Caneja CM, Luna del Castillo JD. Cervilla JA empirical redefinition of delusional disorder and its phenomenology: the DELIREMP study. Compr Psychiatry 2013;54:243-55.

[17] Delespaul P, van Os J. Jaspers was right after all-delusions are distinct from normal beliefs. Br J Psychiatry 2003;183:286.

[18] Walkup J. A clinically based rule of thumb for classifying delusions. Schizophr Bull $1995 ; 21: 323-31$.

[19] Bentall RP, Corcoran R, Howard R, Blackwood N, Kinderman P. Persecutory delusions: a review and theoretical integration. Clin Psychol Rev 2001;21:1143-92.

[20] Rossell SL, Shapleske J, David AS. Sentence verification and delusions: a contentspecific deficit. Psychol Med 1998;28:1189-98.

[21] Martinelli C, Cavanagh K, Dudley RE. The impact of rumination on state paranoid ideation in a nonclinical sample. Behav Ther 2013;44:385-94. https://doi.org/10. 1016/j.beth.2013.02.002.

[22] Freeman D, Startup H, Dunn G, Černis E, Wingham G, Pugh K, Cordwell J, Kingdon D. The interaction of affective with psychotic processes: a test of the effects of worrying on working memory, jumping to conclusions, and anomalies of experience in patients with persecutory delusions. J Psychiatr Res 2013;47:1837-42. https://doi. org/10.1016/j.jpsychires.2013.06.016.

[23] Kohut H. Thoughts on narcissism and narcissistic rage. Psychoanal Study Child 1972 27:360-400.

[24] Gabbard GO. Two subtypes of narcissistic personality disorder. Bull Menninger Clin 1989;53:527-32.

[25] Pincus AL, Ansell EB, Pimentel CA, Cain NM, Wright AGC, Levy KN. Initial construction and validation of the pathological narcissism inventory. Psychol Assess 2009; 21:365-79.

[26] Pincus AL, Roche MJ. Narcissistic grandiosity and narcissistic vulnerability. In: Campbell WK, Miller JD, editors. The handbook of narcissism and narcissistic personality disorder. Hoboken: John Wiley \& Sons; 2011.

[27] Ronningstam EF. Identifying and understanding the narcissistic personality. New York: Oxford University Press; 2005.

[28] Tangney JP, Dearing R. Shame and guilt. New York: Guilford; 2002.

[29] Matos M, Pinto-Gouveia J, Gilbert P. The effect of shame and shame memories on paranoid ideation and social anxiety. Clin Psychol Psychother 2013;20:334-49.

[30] Johnson J, Jones C, Lin A, Wood S, Heinze K, Jackson C. Shame amplifies the association between stressful life events and paranoia amongst young adults using menta health services: implications for understanding risk and psychological resilience. Psychiatry Res 2014;220:217-25.

[31] First MB, Spitzer RL, Gibbon M, Williams BW, Janet BW. Structured clinical interview for DSM-IV axis I disorders, clinician version (SCID-CV). Washington: American Psychiatric Press; 1996.

[32] Mazzi F, Morosini P, De Girolamo G, Lussetti M, Guaraldi GP. SCID-I-Structured Clinical Interview for DSM-IV axis i disorders (Italian Edition). Firenze: OS Organizzazioni Speciali; 2000.

[33] Pfohl B, Blum M, Zimmerman M. Structured interview for DSM-IV. Personality disorders (SIDP-IV). Iowa City: University of Iowa, Dept. Of Psychiatry; 1995.

[34] Fossati A, Pincus AL, Borroni S, Munteanu AF, Maffei C. Are pathological narcissism and psychopathy different constructs or different names for the same thing? A study based on Italian nonclinical adult participants. J Pers Disord 2014;28:394.

[35] Watson D, Clark LA, Tellegen A. Development and validation of brief measures of positive and negative affect: the PANAS scales. J Pers Soc Psychol 1988;54:1063.

[36] Preti A, Marongiu S, Petretto DR, Miotto P, Masala C. Esperienze psichiche inusuali. Studio di validazione della versione italiana del Peters et al Delusions Inventory. Riv Sper Freniatr 2002;126:81-100.

[37] Rocchi MB, Sisti D, Manca S, Siddi S, Mura T, Preti A. Latent class analysis of delusionproneness: exploring the latent structure of the Peters et al. delusions inventory. Nerv Ment Dis 2008;196:620629.
[38] Sisti D, Rocchi MB, Siddi S, Mura T, Manca S, Preti A, Petretto DR. Preoccupation and distress are relevant dimensions in delusional beliefs. Compr Psychiatry 2012: 1039-43.

[39] Widiger TA. Categorical versus dimensional classification: implications from and for research. J Pers Disord 1992;6:287-300.

[40] Melartin TK, Haukka J, Rytsala HJ, Jylha PJ, Isometsa ET. Categorical and dimensional stability of comorbid personality disorder symptoms in DSM-IV major depressive disorder: a prospective study. J Clin Psychiatry 2010;71:287-95.

[41] Skodol AE, Shea MT, Yen S, White CN, Gunderson JG. Personality disorders and mood disorders: perspectives on diagnosis and classification from studies of longitudinal course and familiar associations. J Pers Disord 2010;24:83-108.

[42] Watson D, Tellengen A. Toward a consensual structure of mood. Psychol Bull 1985; 98:219-35.

[43] Tellegen A. Structures of mood and personality and their relevance to assessing anxiety, with an emphasis on self-report. In: Tuma AH, Maser JD, editors. Anxiety and the anxiety disorders. Hillsdale: Erlbaum; 1985.

[44] Hayes F. Introduction to mediation, moderation, and conditional process analysis: A regression-based approach. New York: Guildford Press; 2013.

[45] Schanda H. Paranoia and dysphoria: historical developments, current concepts. Psychopathology 2000;33:204-8.

[46] Lake CR. Hypothesis: grandiosity and guilt cause paranoia; paranoid schizophrenia is a psychotic mood disorder; a review. Schizophr Bull 2008:34:1151-62.

[47] Watson D, Clark LA, Carey G. Positive and negative affectivity and their relation to anxiety and depressive disorders. J Abnorm Psychol 1988;97:346-53.

[48] Wright AG, Lukowitsky MR, Pincus AL, Conroy DE. The higher order factor structure and gender invariance of the Pathological Narcissism Inventory. Assessment 2010;17:467-83.

[49] Johnstone EC, Abukmeil SS, Byrne M, Clafferty R, Grant E, Hodges A, Lawrie SM, Owens, DG Edinburgh high risk study-findings after four years: demographic, attainment and psychopathological issues. Schizophr Res 2000;46:1-15.

[50] Johnstone EC, Ebmeier KP, Miller P, Owens DG, Lawrie SM. Predicting schizophrenia: findings from the Edinburgh High-Risk Study. Br J Psychiatry 2005;186:18-25.

[51] Owens DC, Miller P, Lawrie SM, Johnstone EC. Pathogenesis of schizophrenia: a psychopathological perspective. Br J Psychiatry 2005;186:386-93.

[52] Yung AR, Phillips LJ, Yuen HP, Francey SM, McFarlane CA, Hallgren M, McGorry PD. Psychosis prediction: 12-month follow up of a high-risk ("prodromal") group. Schizophr Res 2003;60:21-32.

[53] Yung AR, Buckby JA, Cosgrave EM, Killackey EJ, Baker K, Cotton SM, McGorry PD. Association between psychotic experiences and depression in a clinical sample over 6 months. Schizophr Res 2007:91:246-53.

[54] Tonna M, De Panfilis C, Provini C, Marchesi C. The effect of severity and personality on the psychotic presentation of major depression. Psychiatry Res 2011;190:98-102.

[55] Tonna M, De Panfilis C, Marchesi, C. Mood-congruent and mood-incongruent psychotic symptoms in major depression: the role of severity and personality. J Affect Disord 2012;141:464-468.

[56] Pincus AL, Pathological Narcissism Lukowitsky MR. Narcissistic personality disorder. Annu Rev Clin Psychol 2010;6:421-46.

[57] Cain NM, Pincus AL, Ansell EB. Narcissism at the crossroads: phenotypic description of pathological narcissism across clinical theory, social/personality psychology, and psychiatric diagnosis. Clin Psychol Rev 2008;28:638-56.

[58] Straus EW. Die Scham als historiologisches Problem. Schweiz Arch Neurol Psychiatr 1933;31:1-5.

[59] Binswanger L. Schizophrenie. Neske Verlag: Pfullingen; 1957.

[60] Muncie W. Psychobiology and psychiatry. St. Louis: MO.CV Mosby; 1939.

[61] Kendler KS, Masterson CC, Davis KL. Psychiatric illnesses in first-degree relatives of patients with paranoid psychoses, schizophrenia and medical illness. Br J Psychiatry 1985;147:524-31.

[62] Winokur G. Familiar psychopathology in delusional disorder. Compr Psychiatry $1985 ; 20: 241-8$

[63] Bogren M, Mattisson C, Isberg PE, Munk-Jørgensen P, Nettelbladt P. Incidence of psychotic disorders in the 50 year follow up of the Lundby population. Aust N Z J Psychiatry $2010 ; 44: 31-9$. 